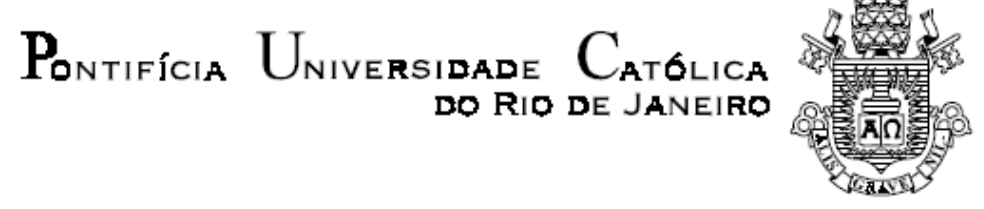

Maria de Lourdes Morgado Coelho

\title{
UM MERGULHO NA FICÇÃO DA HISTÓRIA
}

\section{Dissertação de Mestrado}

Dissertação apresentada como requisito parcial para obtenção do grau de Mestre pelo Programa de Pós-Graduação em Letras do Departamento de Letras do Centro de Teologia e Ciências Humanas da PUC-Rio.

Orientador: Prof. Ronaldo Menegaz

Rio de Janeiro

Setembro de 2009 
Pontifícia Universidade Catolica $_{\text {a }}$

DO RIO DE JANEIRO

Maria de Lourdes Morgado Coelho

\section{UM MERGULHO NA FICÇÃO DA HISTÓRIA}

Dissertação apresentada como requisito parcial para obtenção do grau de Mestre pelo Programa de Pós-Graduação em Letras do Departamento de Letras do Centro de Teologia e Ciências Humanas da PUC-Rio. Aprovada pela Comissão Examinadora abaixo assinada.

Prof. Ronaldo Menegaz

Orientador Departamento de Letras - PUC-Rio

Profa. Vera Lucia Follain de Figueiredo Departamento de Letras - PUC-Rio

Profa. Amélia Maria Cavalcanti Lacombe UFRJ

Prof. Paulo Fernando Carneiro de Andrade Coordenador Setorial do Centro de Teologia e Ciências Humanas - PUC-Rio

Rio de Janeiro, 15 de setembro de 2009. 
Todos os direitos reservados. É proibida a reprodução total ou parcial do trabalho sem autorização da universidade, da autora e da orientadora.

\section{Maria de Lourdes Morgado Coelho}

Graduou-se em Letras - Licenciatura Plena em Português e Literatura Brasileira e Portuguesa, pela PUC-Rio, em 1973. Iniciou sua carreira de professora lecionando Português e Literatura no Departamento de Letras da PUC-Rio. Foi Editora-Executiva de uma publicação mensal, um House Organ: ADEMI - Associação dos Dirigentes do Mercado Imobiliário. Foi repórter e redatora da "Revista Bolsa" - da Bolsa de Valores do Rio de Janeiro. É escritora e dois livros foram publicados pela PUC - Rio em colaboração com a Profa. Amélia Lacombe.

Ficha Catalográfica

Coelho, Maria de Lourdes Morgado

Um mergulho na ficção da história / Maria de Lourdes Morgado Coelho ; orientador: Ronaldo Menegaz. - 2009.

109 f. : il. ; $30 \mathrm{~cm}$

Dissertação (Mestrado em Letras)Pontifícia Universidade Católica do Rio de Janeiro, Rio de Janeiro, 2009.

Inclui bibliografia

1. Letras - Teses. 2. Ficção. 3. Efeito de real. 4. Verossimilhança. 5. Fantasia. 6. Narrativa. 7. Discurso. 8. História. 9. Verdade. 10. Mentira. 11. Memória realidade. 12. Engano. 13. Razão. I. Menegaz, Ronaldo. II. Pontifícia Universidade Católica do Rio de Janeiro. Departamento de Letras. III. Título.

CDD: 800 


\section{AGRADECIMENTOS}

Ao meu avô, meu pai e à avozinha mais linda do universo.

À Amélia Lacombe, eterna professora, minha estrela guia, apoio incondicional.

À Affonso Romano de Sant'Anna, eterno professor, generosidade e saber. Poeta Maior que, felizmente, cruzou meu caminho.

Às Professoras Vera Follain e Eliana Yunes pela enorme sensibilidade e competência.

Ao meu orientador, Ronaldo Menegaz, doutor em respeito e afeto.

À minha família:

Ao meu marido, Antonio Carlos, o primeiro leitor emocionado de todos os meus escritos.

Aos meus três filhos: Marcelo, Rodrigo e Gabriela, fachos de luz e razão da minha existência... De vocês sou apenas o rascunho.

Às minhas mães, Theresa e Glorinha, queridos alicerces da minha caminhada.

A todos os amigos especiais.

À Alécia Moura, amiga de todas as horas.

A todos os Excelentes Professores da Pós-Graduação da PUC-RIO.

Aos muitos amigos que me ajudaram na confecção desta Tese.

À PUC, meu paraíso encantado, e à estrutura de excelência que nos atende. 


\section{Resumo}

Coelho, Maria de Lourdes Morgado; Menegaz, Ronaldo. Um Mergulho na Ficção da História Rio de Janeiro, 2009. 109p. Dissertação de Mestrado - Departamento de Letras, Pontifícia Universidade Católica do Rio de Janeiro.

Vivemos num mundo em crise. E essa crise é também cultural. Se o multiculturalismo favorece o diálogo entre inúmeras áreas da cultura, rouba-lhes muitas vezes, a especificidade, dilui suas marcas. E isso acontece, neste momento com a história, com a ficção e a realidade.

A concepção de História que decidimos interpretar, nos parecia uma narrativa de estrutura simples, quando esta se revelou uma narrativa de estrutura complexa ao seguir os passos da ficção, oscilando entre a tragédia e o folhetim. Uma história pode ser uma narração histórica ou uma fábula, dependendo de "como se conta" esta história.

O mesmo ocorre com a ficção que pode, muitas vezes, testemunhar a verdade de um fato histórico.

Essa aproximação entre estas duas práticas discursivas é o ponto crucial da nossa investigação, verificar como se comportam os discursos histórico e ficcional, ambos fabricados e elaborados pelo fetichismo dos fatos na produção histórico-ficcional.

Este trabalho apresenta os resultados de uma pesquisa que se debruçou sobre o viés que deflagra a proximidade das narrativas da História e da Ficção. Enfocou representações sociais e discursivas nas investigações feitas pela análise das obras: A Carta de Caminha em diálogo com o Diário de Bordo de Colombo e Peregrinação de Barnabé das Índias de Mário Cláudio, "A Implosão da Mentira" de Affonso Romano de Sant'Anna, "O Conto Da Ilha Desconhecida" de José Saramago e "O Vendedor de Passados" de José Eduardo Agualusa.

Investigamos, portanto, vários gêneros literários, tais como: uma carta, enquanto documento histórico, uma poesia, um conto e um romance. Atravessamos o Atlântico dos Séculos XV e XVI até o atual Século XXI, viajando literariamente entre Portugal, Brasil e África. 


\section{Palavras-chave}

Ficção, Efeito de real, Verossimilhança, Fantasia, Narrativa, Discurso, História, Verdade, Mentira, Memória, Realidade, Engano, Razão. 


\section{Abstract}

Coelho, Maria de Lourdes Morgado; Menegaz, Ronaldo (Advisor).

A Dive in the Fiction of History. Rio de Janeiro, 2009. 109p. MSc. Dissertation - Departamento de Letras, Pontifícia Universidade Católica do Rio de Janeiro.

We live in a world in crisis. And this crisis is also cultural. If multiculturalism encourages the dialogue between different areas of culture, it steals, many times, the specificity, dilutes its marks. And it happens, at this moment, with history, with fiction and reality.

The conception of history that we decided to interpret, seemed like a narrative of simple structure, when it revealed to be a narrative of complex structure by following the steps of fiction, oscillating between tragedy and feuilleton. A story can be a historical narrative or a fable, depending on "how you tell" this story.

The same occurs with fiction that can, many times, witness the truth of a historical fact.

This approximation between these two discursive practices is the crucial point of our research, verifying how historical and fictional discourses behave, both manufactured and elaborated by the fetishism of facts in historical-fiction production.

This paper presents the results of a study that bent over the bias that outbreak the proximity of history and fiction narratives. It has focused social and discursive representations in the investigations made by the analysis of the literary works: "A Carta de Caminha em diálogo com o Diário de Bordo de Colombo e Peregrinação de Barnabé das Índias" by Mário Cláudio, "A Implosão da Mentira" by Affonso Romano de Sant'Anna, "O Conto Da Ilha Desconhecida” by José Saramago and "O Vendedor de Passados" by José Eduardo Agualusa.

Therefore, we investigated several literary genres, such as: a letter, as a historical document, a poem, a tale and a romance. We crossed the Atlantic in the $\mathrm{XV}$ and XVI century until the present century XXI, traveling through literacy between Portugal, Brazil and Africa. 


\section{Keywords}

Effect of Reality, Verisimilitude, Fantasy, Narrative, Speech, Construct, Truth, Memory, Reality, Mistake, Reason. 


\section{Sumário}

1. Introdução 13

2. A Implosão da Mentira 16

$\begin{array}{lll}2.1 \text { Análise } & 19\end{array}$

3. A Carta de Caminha: Visões do Paraíso 28

3.1 A Carta de Pero Vaz de Caminha 31

3.2 Considerações 34

3.3 A Carta de Caminha e o Diário de Colombo 35

3.4 Peregrinação de Barnabé das Índias 37

3.5 Os Lusíadas $\quad 39$

3.6 Considerações Finais 42

4. História e Ficção 50

4.1 Memória 53

5. A llha Desconhecida 69

6. A Força do Relato: O Vendedor de Passados 84

7. Conclusão 99

8. Bibliografia Geral 104

9. Anexo - Entrevista com José Eduardo Agualusa 107 


\section{Lista de Figuras}

Fig. 1- llustração de Capa - montagem da própria autora desta obra.

Fig. 2- A Implosão da Mentira - montagem da própria autora desta obra.

Fig. 3- Carta de Caminha - Starte.

Fig. 4- História e Ficção - Starte.

Fig. 5- Foto da direita, Charles Whelan/AFP e foto da esquerda, Zhow Liang/AP 2008

Fig. 6- A Ilha Desconhecida(Título criado pela autora).Pintura de Claude Monet.

68

Fig. 7- A força do Relato. Ouriço Arquitetura e Design.

83 


\section{INSTANTES}

Se eu pudesse viver novamente a minha vida, na próxima trataria de cometer mais erros.

Não tentaria ser tão perfeito, relaxaria mais.

Seria mais tolo ainda do que tenho sido, na verdade bem poucas coisas levaria a sério.

Seria menos higiênico.

Correria mais riscos, viajaria mais, contemplaria mais entardeceres, subiria mais montanhas, nadaria mais rios.

Iria a mais lugares onde nunca fui, tomaria mais sorvete e menos lentilha, teria mais problemas reais e menos problemas imaginários.

$\mathrm{Eu}$ fui uma dessas pessoas que viveu sensata e produtivamente cada minuto da vida, claro que tive momentos de alegria.

Mas se pudesse voltar a viver, trataria de ter somente bons momentos.

Porque, se não sabem, disso é feita a vida, só de momentos, não percas o agora.

Eu era um desses que nunca ia a parte alguma sem um termômetro, uma bolsa de água quente, um guarda-chuva e um pára-quedas. Se voltasse a viver, começaria a andar descalço no começo da primavera e continuaria assim até o fim do outono.

Daria mais voltas na minha rua, contemplaria mais amanheceres e brincaria com mais crianças, se tivesse outra vez uma vida pela frente.

Mas já viram, tenho oitenta e cinco anos e sei que estou morrendo. 